\title{
Overweight and Metabolic and Hormonal Parameter Disruption Are Induced in Adult Male Mice by Manipulations During Lactation Period
}

\author{
ALBERTO LOIZZO, STEFANO LOIZZO, GABRIELLA GALIETTA, STEFANIA CAIOLA, SANTI SPAMPINATO, \\ GABRIELE CAMPANA, GIUSEPPE SEGHIERI, GIOVANNI GHIRLANDA, AND FLAVIA FRANCONI
}

Departments of Drug Research and Evaluation [A.L., S.L., G.G.], and Hematology, Oncology, and Molecular Medicine [S.C.], Istituto Superiore di Sanità, 00161 Roma, Italy; Department of Pharmacology [S.S., G.C.], University of Bologna, 40010 Bologna, Italy; Department of Internal Medicine [G.S.], Spedali Riuniti, 51100 Pistoia, Italy; Department of Internal and Geriatric Medicine [G.G.], Catholic University, 00168 Roma, Italy; Department of Pharmacology and Center for Biotechnology Development and Biodiversity Research [F.F.], University of Sassari, 07100 Sassari, Italy

\begin{abstract}
Neonatal manipulations (10 min of maternal separation plus s.c. sham injection, daily for the first $21 \mathrm{~d}$ of life) determine overweight in male adult mice. In this work, we investigated the mechanisms underlying mild obesity and the alteration of caloric balance. Neonatally manipulated mice become overweight after onset of maturity, showing increased fat tissue and hypertrophic epididymal adipocytes. Increase in body weight occurs in the presence of a small increase in daily food intake (significant only in the adult period) and the absence of a decrease in spontaneous locomotor activity, while the calculated caloric efficiency is higher in manipulated mice, especially in adulthood. Fasting adult animals show hyperglycemia, hyperinsulinemia, hypertriglyceridemia, hypercholesterolemia, and hyperleptinemia. Soon after weaning and in the adulthood, plasma corticosterone and adrenocorticotropin (ACTH) are also significantly increased. Thus, neonatal manipulations in nongenetically susceptible male mice program mild obesity, with metabolic and hormonal alterations that are similar to those found in experimental models of diabetes mellitus, suggesting that this metabolic derangement may have at least part of its roots early on in life and, more interestingly, that psychological and nociceptive stimuli induce these features. (Pediatr Res 59: 111-115, 2006)
\end{abstract}

$\mathrm{I}^{\mathrm{n}}$ recent years, several animal studies and human epidemiologic data support the notion that fetal and neonatal events may have long-term or permanent effects and become characteristic of the individual. These observations have been proposed to exemplify the phenomenon of "programming," whereby a stimulus and/or stressor acting in critical periods during early life can alter the development of organs, causing permanent dysfunction and ultimately resulting in disease (1). In men, many observations suggest that two and possibly three critical periods exist for the development of obesity and its complications in the adulthood. These include gestation and

Received January 31, 2005; accepted July 6, 2005.

Correspondence: Alberto Loizzo, M.D., Istituto Superiore di Sanità, viale Regina Elena, 299-00161 Rome, Italy; e-mail: alberto.loizzo@iss.it

Supported in part by Italian National Institute of Health Research Programs "Developmental Pharmacology" and "New Preventive and Therapeutic Approach for an Emerging Risk for the Adult Woman and Man Following Fetal and Neonatal Programming Disruption" and in part with the contribution of GIO.I.A Foundation, Pisa, and of Fondazione Cassa di Risparmio Pistoia e Pescia.

DOI: 10.1203/01.pdr.0000190575.12965.ce early infancy, the period of adiposity rebound that occurs between 5 and $7 \mathrm{y}$ of age, and adolescence (2). Obesity has epidemic diffusion and obese adults are nearly twice as likely to suffer from chronic disease (3). Moreover, obesity is the main force in accelerating the increased incidence of type 2 diabetes mellitus, being the single most effective contributor to the pathogenesis of the disease: obesity and type 2 diabetes mellitus have epidemic diffusion and their incidence is rapidly increasing (4). One of the major determinants is a genetic predisposition; nevertheless, genetically susceptible individuals may not develop the disease, provided that they avoid certain risk factors (5). Among these risk factors, the importance of manipulations that induce modification of the metabolic programming such as growth deficit, determined by malnutrition during fetal and neonatal life, has been shown (6). This is in line with the fact that most pancreatic islet growth in both humans and rodents takes place during the fetal and neonatal periods, as well as maturation patterns of the hypothalamic-pituitary-adrenal axis (HPA) (6-8). Indirect evidence of these relationships is underlined by the fact that an occult Cushing syndrome has been shown in type 2 diabetes mellitus patients (9).

Some authors emphasize the importance of the central nervous system in the development of obesity or overweight connected with the metabolic syndrome and type 2 diabetes mellitus (10). Indeed, mice without brain insulin receptors are obese and have high plasma levels of insulin, leptin, and triglycerides (11). In addition, animals bearing lesions on the ventromedial hypothalamic nuclei (VMH) have hyperinsulinemia with normoglycemia, hypertriglyceridemia, and hypercholesterolemia (12). Furthermore, Obici et al. (13) showed

Abbreviations: ACTH, adrenocorticotropin; GC, glucocorticoids; HPA, hypothalamic-pituitary-adrenal axis; TNF- $\alpha$, tumor necrosis factor $\alpha$; VMH, ventromedial hypothalamic nuclei 
that hypothalamic insulin signaling is required for the inhibition of glucose production. Impaired insulin signaling in the hypothalamus can play a role in the development of obesity in Zucker rats, which is a model of insulin resistance (14). Indeed, Das (10) suggests that a close association exists between hypothalamus islet function and cytokines. Previously, we showed that male adult mice submitted to neonatal manipulations are overweight and their splenocytes produce more interleukin-2, interferon gamma, and tumor necrosis factor $\alpha$ (TNF- $\alpha)(15,16)$. This is probably because obesity is associated with chronic mild inflammatory response, and in this contest, the overexpression of TNF- $\alpha$ can contribute to insulin resistance (17).

Considering that the development of obesity in adult humans may have its roots in early life events $(1,2,6,18)$, considering that chronic stress and obesity are bound together through several hormonal and metabolic mechanisms, and considering that obesity is the leading determinant in the development of type 2 diabetes mellitus, it seems interesting to evaluate whether the association of psychological and nociceptive manipulations in neonatal life may produce obesity and hormonal/metabolic derangement features in male adult mice $(1,2,15,16)$.

\section{METHODS}

All procedures were carried out in accordance with the guidelines of the Council of European Communities and the approval of Bioethical Committee of the Italian National Institutes of Health

Animal general procedures. All mice were housed in a central facility and maintained under controlled conditions of normal humidity and temperature, with standard alternating 12-h periods of light and darkness. Different series of pregnant multiparous Laboratory-born CD-1 mice (Charles River Italia, Calco, Italy) arrived at the $\mathrm{d} 14$ of gestation in the vivarium where all animals were kept. Animals had free access to water and food. Mucedola S.r.l. (Settimo Milanese, Italy) supplied the diet, which contained $3.95 \mathrm{kcal} / \mathrm{g}$ equivalent to assimilable $2.7 \mathrm{kcal} / \mathrm{g}$. All experiments were performed in winter to avoid seasonal variation in receptors sensitivity (16).

Prenatal and neonatal procedures. The experimental procedures were performed according to Loizzo et al. (16). Briefly, starting on the 19th day of pregnancy, females were examined twice daily (at 08:00 and 16:00) for the presence of pups. In about $12 \mathrm{~h}$ from the detection of the pups, litters of homogeneous size (13 \pm 1 subjects) were put together and randomly culled to six male pups so that all pups were randomly cross-fostered. In addition, male pups have a homogeneous weight to avoid interference induced by impairment of growth, which is an important determinant in the onset of type 2 diabetes mellitus in adults (6). To avoid manipulation of control mice, we preferred to adopt the protocol with complete litters receiving the same treatment to the alternative, in which half the litter would receive one treatment, and the other half a different treatment. The litters were randomly assigned to one of the following groups (each group consisting of two litters at least): 1) control group: the pups were left undisturbed, but pups and dams were removed at the same time and put in a clean cage twice weekly; 2) manipulated mice: for $21 \mathrm{~d}$, the pups were removed daily $(10 \mathrm{~min})$ from the home cage and grouped in a container with fresh bedding material. During the period of maternal deprivation, each pup was gently picked up with a gloved hand, weighed, and injected subcutaneously in the back with sterile saline solution $(1 \mathrm{~mL} / \mathrm{kg}$ ) with a microsyringe (26-gauge needle). After this, they were returned to the home cage with the mother. Procedures were always performed by the same experimenter.

Ten minutes of maternal separation alone was unable to induce overweight in adult mice. In fact at $135 \mathrm{~d}$ of age, the body weight (grams) of the maternal separated mice and of controls was $51.8 \pm 1.0$ and $52.5 \pm 1.3$, respectively, while manipulated mice (mice that underwent maternal separation plus injection) had a mean body weight of $61.8 \pm 0.9 \mathrm{~g}$ (Table 1). Therefore, the maternal separated/not injected mice group was dropped from final experiments.

Postweaning protocol. At postnatal d 21, animals were rehoused in postweaning cages, three animals in each cage to avoid isolation-induced stress. Animals were weighed every week and used at the ages indicated in the figures and tables.

Locomotor activity. After a 120-min habituation session in their home cages, motor activity of the three animals was performed according to Heal (19). A modified intruder alarm device, based on a microwave Doppler system connected with a computer, to count the number of the movements per time unit and to store the data, monitored the motor activity. The time constant was minimized and pulse former was introduced so that the movement of its head, but not the flick of its ear triggered the meter. The succession of cages was randomly generated in each session $(30 \mathrm{~min})$, which was performed between 09:00 and 12:00 $\mathrm{h}$ and between 18:00 and 21:00 h, respectively.

Daily food and water intake and body weight and length. Daily food and water intake and body weight were measured at the times indicated in tables. The mice were presented with the same amount of food, and their intake was measured the following day by subtracting the uneaten food and correcting the food intake for spillage. We preferred the less precise measure of group (three mice) food consumption because isolation is considered a potent stressor. Caloric efficiency was also computed, as the body weight gained in grams divided by the estimated cumulative food ingested in grams from $\mathrm{d}$ 23 to d 118 of life (20). At $135 \mathrm{~d}$ old, one set of animals was anesthetized and killed with an overdose of sodium pentobarbital, and body length was measured from the nose to the anus.

Morphometric image analysis. In the other groups of 120-d-old mice, epididymal fat pads were dissected and washed in warm saline, blotted, and weighed. Then they were fixed in $4 \%$ paraformaldehyde for $24 \mathrm{~h}$, included in paraffin and sliced in $10-\mu \mathrm{m}$ thick sections. These sections were mounted onto gelatin-coated glass slides. The morphometric imagine analysis of tissue was performed with VIDAS-VIDEOPLAN 2.4 (Kontrol-bildanalyse GmbH, Munich, Germany) connected to a light microscope. Two slices for each animal and six randomly selected fields per slice were considered. Data analyses give the following parameters: minimum and maximum adipocyte diameters, mean area, and estimated mean volume.

Plasma glucose, insulin, lipids, leptin, corticosterone, and ACTH. At $120 \mathrm{~d}$ of life, trunk blood samples were collected, between 09:00 and 12:00 $\mathrm{h}$, after rapid decapitation and after $14 \mathrm{~h}$ of fasting. Blood was collected in heparinized or EDTA tubes centrifuged at $3500 \times g$ for 10 min and kept at $-80^{\circ} \mathrm{C}$ until analysis. For the dose of leptin, $\mathrm{ACTH}$, and corticosterone, the blood samples were placed on ice; these parameters were performed on nonfasted mice to avoid the stress due to the fasting condition. Glucose, total cholesterol, triglycerides, and phospholipids were measured in duplicate with a commercial kit (Boehringer Mannheim $\mathrm{GmbH}$ ). The plasma insulin level was determined in duplicate, using commercial radioimmunoassay (RIA) kits (Linco Research, St. Charles, MO). Intra- and interassay coefficients of variation were $<4.5 \%$. Plasma leptin levels were determined in triplicate, using commercial RIA kits (Linco Research). Intra- and interassay coefficients of variation were $<10 \%$. Corticosterone levels were assayed in duplicate in a single assay using an RIA kit (ICN, Costa Mesa, CA) with intraassay coefficients of variations $<2 \%$. The plasma levels of immunoreactive ACTH were measured by RIA with a double-antibody precipitation assay; we used human ACTH antiserum and human ACTH standard obtained from Dr. A.F. Parlow (Harbor-UCLA Medical Center) and [ ${ }^{125}$ I]iodotyrosyl 2-ACTH-(139) (Amersham Biosciences, Milan). The antibody recognizes mouse ACTH-

Table 1. Body weight (grams) at different ages (in days) in the two experimental groups

\begin{tabular}{lccccc}
\hline \multicolumn{1}{c}{ Group } & $25 \mathrm{~d}$ & \multicolumn{1}{c}{$60 \mathrm{~d}$} & \multicolumn{1}{c}{$95 \mathrm{~d}$} & $120 \mathrm{~d}$ & \multicolumn{1}{c}{$135 \mathrm{~d}$} \\
\hline Controls & $23.3 \pm 0.4$ & $45.5 \pm 0.6$ & $49.2 \pm 0.5$ & $51.1 \pm 0.6$ & $52.5 \pm 1.3$ \\
Manipulated animals & $24.5 \pm 0.4$ & $48.4 \pm 0.8^{*}$ & $54.6 \pm 0.8 \dagger$ & $58.7 \pm 1.0 \dagger$ & $61.8 \pm 0.9 \dagger$ \\
\hline
\end{tabular}

Values are mean \pm SEM of 12 animals.

$* p<0.05$.

$\dagger p<0.001$ versus respective controls. 
(1-39), and there is no cross-reactivity with other peptides derived from the proopiomelanocortin precursor.

Statistical analysis. Values are expressed as mean or median \pm SEM The differences were tested by analysis of variance (ANOVA) and analyzed using Dunnett's comparison tests. Cell volume distribution was evaluated through $\chi^{2}$ analysis. The difference among groups of data were considered significant when $p<0.05$.

\section{RESULTS}

Body weight, food and water intake, body length, epididymal fat pad, caloric efficiency, and spontaneous motor activity. At weaning, both groups did not show significant differences in body weight (Table 1). Indeed, manipulated mice weighed significantly more that did control mice at approximately $60 \mathrm{~d}$ of age and thereafter (Table 1), but at $135 \mathrm{~d}$ of age, they did not present any significant differences in body length, which was $11.7 \pm 0.1 \mathrm{~cm}(n=20)$ and $11.7 \pm 0.1 \mathrm{~cm}(n=20)$ in control and manipulated groups, respectively. Moreover, no significant changes in water consumption were observed (data not shown). At $135 \mathrm{~d}$ of age, the manipulated mice had larger epididymal fat pads $(2.5 \pm 0.2 \mathrm{~g})$ than controls $(1.2 \pm 0.3 \mathrm{~g})(n=12$ for each group; $p<0.001)$ and a significant increase in volume of epididymal adipocytes when compared with control animals is recorded in Table 2.

To understand the source of mild obesity, three conditions were evaluated, i.e. the daily food consumption, the caloric efficiency, and spontaneous locomotor activity. As a whole, the cumulated food intake was not consistently different in the two groups (Table 3). From d 23 to d 118 of age, the difference between manipulated and control animals in total estimated food intake was $5.1 \mathrm{~g}$, which means an average increase of $0.054 \mathrm{~g} / \mathrm{d}$ per single manipulated mouse over control. Considering that this minute amount of food was equivalent to $0.15 \mathrm{kcal}$ (mouse food produces $2.7 \mathrm{kcal} / \mathrm{g}$ ), the average gap in caloric intake was about $14 \mathrm{kcal}$ at $95 \mathrm{~d}$ of life, which means an elevation of stored fat of about $1.6 \mathrm{~g}$. This could justify $20 \%$ of the total weight increase of $7.6 \mathrm{~g}$ average difference at $120 \mathrm{~d}$ of life (Table 1). However, when the adult period (78-118 d) was considered, the estimated food consumption was significantly different in manipulated animals $(p<0.02)$.

Another important determinant in the control of body weight is the energy cost of food assimilation; therefore, the caloric efficiency (grams of body weight gained divided by grams of food ingested) was calculated. From d 23 to $\mathrm{d} 118$ of life, the overall caloric efficiency was $0.041 \pm 0.002$ and $0.051 \pm 0.002$ in controls and manipulated mice, respectively. Indeed, before the onset of frank overweight (23-58 d of age), there is an increase, being $0.096 \pm 0.005$ and $0.101 \pm 0.004$ in control and manipulated mice, respectively. After the onset of overweight (78-118 d of age), the caloric efficiency was almost doubled in manipulated animals $(0.025 \pm 0.003)$ in

Table 2. Estimated epididymal adipocytes volume

\begin{tabular}{ccc}
\hline Cell volume & Control & Manipulated \\
\hline $0.1-2.5 \mu \mathrm{m}^{3} \times 10^{4}$ & $94 \%$ & $40 \%$ \\
$2.6-5.0 \mu \mathrm{m}^{3} \times 10^{4}$ & $4 \%$ & $18 \%$ \\
$>5.0 \mu \mathrm{m}^{3} \times 10^{4}$ & $2 \%$ & $42 \%$ \\
\hline
\end{tabular}

Values are mean of six animals. $\chi^{2}=58.32 ; p<0.01$. comparison with controls $(0.012 \pm 0.001)(p<0.001)$. These results show the same temporal trend as the above data found for food consumption and confirm these data from another point of view.

The energy cost for physical activity is another important clue for controlling body weight; therefore, the spontaneous locomotor activity was examined before the onset of overweight (d 44), near the onset of overweight (d 51) at the beginning of the overweight (around d 58) and in adult mice (78- to 118-d-old mice). In the light phase, motor activity of manipulated animals was not significantly reduced (about $4.8 \%$ ) versus controls. No changes were detected during dark phase. Thus, sum of total locomotor activity of control and manipulated mice was $8954 \pm 5123$ and $8623 \pm 3709$ (arbitrary units), respectively ( $n=3$ cages for each group; $p=$ not significant).

Plasma levels of glucose, insulin, lipids, leptin, corticosterone, and ACTH. In 120-d-old manipulated mice, fasting plasma glucose was significantly elevated at about $71 \%$ (Table 4). Triglycerides and total cholesterol were significantly increased by about $33 \%$ and $13 \%$, respectively (Table 4 ) in the absence of significant changes of phospholipid levels. Important changes were found in plasma levels of hormones because plasma insulin levels were significantly higher (about 125\% higher) in manipulated versus control animals (Table 4). The manipulated adults also had a significantly higher plasma level of the adipocytes hormone leptin, which was significantly elevated by about $53 \%$ (Table 4). The two hormones used to evaluate the involvement of HPA, i.e. ACTH and corticosterone (Fig. 1), were also significantly increased in manipulated mice when compared with the control group not only at $21 \mathrm{~d}$ of age, soon after the end of manipulations, but in addition, the two hormones were increased in adulthood at 4 mo of age.

\section{DISCUSSION}

Data reported here show that mild but repetitive neonatal psychological and painful manipulations induce long-lasting or permanent hormonal and metabolic alterations in nongenetically vulnerable mice. These conditions are similar to those induced by the electrodestruction of VMH in rats, those present in the phenotype of knockout mice for brain insulin receptors and the phenotypic features similar to the type 2 diabetes mellitus in human patients $(11,12)$. In fact, the present experimental paradigm results in overweight animals, with hyperglycemia, hyperinsulinemia, hyperleptinemia, hyperlipidemia, an increase in triglycerides, which is higher than total cholesterol, and a high plasma level of ACTH and corticosterone (21).

At the end of lactation, both groups have a very similar body weight. Thus, it is unlikely that adult body weight alterations are produced by modifications in feeding habit or consumption during lactation. This is an important finding because impaired growth during fetal life and during lactation can cause alteration in pancreas programming $(6,22)$. Indeed, as previously shown mild obesity attained with the present model is characterized by a relatively late onset (about $60 \mathrm{~d}$ of life), coincidentally with the onset of sexual maturity $(16,23)$. Overweight mice have increased epididymal fat pads and 
Table 3. Daily food intake (grams) in control and neonatally manipulated male mice at different ages (days)

\begin{tabular}{|c|c|c|c|c|c|c|c|c|c|}
\hline Group & 23 & 30 & 37 & 51 & 58 & 78 & 88 & 98 & 108 \\
\hline Control mice & $11.5 \pm 0.3$ & $20.6 \pm 0.4$ & $21.9 \pm 0.9$ & $22.6 \pm 0.3$ & $24.7 \pm 0.4$ & $20.8 \pm 0.2$ & $21.3 \pm 0.2$ & $21.2 \pm 0.1$ & $21.4 \pm 0.1$ \\
\hline Manipulated mice & $11.5 \pm 0.2$ & $22.2 \pm 0.4$ & $22.4 \pm 0.3$ & $22.6 \pm 0.3$ & $23.8 \pm 0.6$ & $21.3 \pm 0.2$ & $21.7 \pm 0.4$ & $21.6 \pm 0.1$ & $21.7 \pm 0.2$ \\
\hline
\end{tabular}

Values are mean \pm SEM of at least three cages, each containing three animals (cumulative daily food intake). Estimated cumulative food intake is significantly higher in manipulated mice in the age range of $78-118 \mathrm{~d}(p<0.02)$.

Table 4. Effect of neonatal manipulation on fasting plasma levels of insulin, glucose, triglycerides, total cholesterol, phospholipids, and leptin in 120-d-old mice

\begin{tabular}{lcc}
\hline \multicolumn{1}{c}{ Parameter } & Control & Manipulated \\
\hline Glucose $(\mathrm{mg} / \mathrm{dL})$ & $52.0 \pm 1.8$ & $89.2 \pm 3.4^{*}$ \\
Triglycerides $(\mathrm{mg} / \mathrm{dL})$ & $69.9 \pm 2.4$ & $93.0 \pm 3.9^{*}$ \\
Total cholesterol $(\mathrm{mg} / \mathrm{dL})$ & $97.9 \pm 3.1$ & $110.2 \pm 3.4 \dagger$ \\
Phospholipids $(\mathrm{mg} / \mathrm{dL})$ & $165.1 \pm 5.1$ & $175.7 \pm 4.3$ \\
Insulin $(\mathrm{pmol} / \mathrm{L})$ & $24 \pm 0.6$ & $54 \pm 1.2 \ddagger$ \\
Leptin $(\mathrm{ng} / \mathrm{mL})$ & $4.46 \pm 0.39$ & $6.88 \pm 0.45^{*}$ \\
\hline
\end{tabular}

Values are the mean of six mice \pm SEM.

$* p<0.001$ versus respective controls.

$\dagger p<0.05$ versus respective controls.

$\ddagger p<0.01$ versus respective controls.

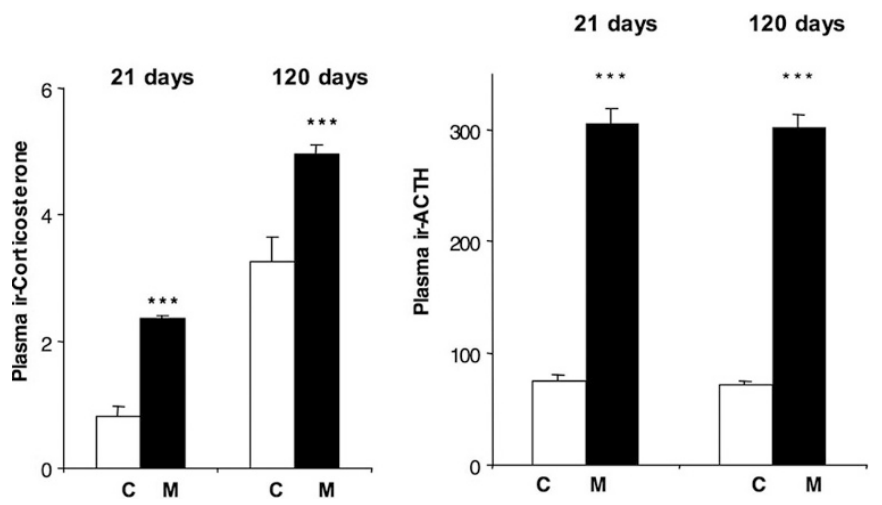

Figure 1. Plasma corticosterone and plasma ACTH levels, at different ages in controls and neonatally manipulated mice. Values are means \pm SEM of six mice for each experimental group. $* * * p<0.001 v s$ respective controls. Abscissa: C, control animals; M, manipulated animals. Ordinate: Plasma ir-corticosterone ( $\mu \mathrm{g} / \mathrm{dL})$; plasma ir-ACTH $(\mathrm{pg} / \mathrm{mL})$. ir, immunoreactive.

hypertrophic adipocytes and do not present consistent variations in daily spontaneous locomotor activity but do present a small increase in food intake. Nevertheless, when the total life food intake is considered after weaning, it justifies $20 \%$ of the total body weight increase over controls. Adult manipulated male mice had $20 \%$ increase in caloric efficiency when was calculated from 23 to $118 \mathrm{~d}$ of life. But the increment in caloric efficiency reaches about $100 \%$ when calculated after the onset of overweight. This is in line with previous findings $(22,24)$. The resting metabolic rate has not been investigated and this could be a bias of the study, but whether a reduced thermal response to food is a mechanism for the extra energy needed is still a matter of debate (25).

Obesity was associated with a chronic inflammatory response, and it has also been shown that the inflammatory cytokine TNF- $\alpha$ contributes to insulin resistance $(17,26)$. In this contest, it is important to underline that splenocytes of mice submitted to an identical experimental paradigm produce more cytokines of the proinflammatory type, suggesting that the appearance of obesity (and perhaps of the type 2 diabetes mellitus) could be linked to an inflammatory reaction (16). Although in the presence of obesity, the inflammatory response appears to be triggered and to reside mainly in adipose tissue, it is not possible to exclude that obesity also induces an inflammatory response in other metabolically critical sites.

The increased insulin plasma level may include altered structure and function of the endocrine pancreas and/or insulin sensitive target tissues. In humans, the impairment of insulin sensitivity in some individuals may be compensated by enhanced insulin secretion, while in others, insulin secretion is not sufficient to overcome insulin resistance. Consequently, glucose intolerance develops, such as in our manipulated mice. The high insulin plasma levels suggest that in our mice psychological and painful manipulations administered early in life are able to modify pancreas programming and/or the mechanisms involved in pancreas functionality and that this occurs in the absence of growth deficit during lactation.

The manipulated overweight mice also have a marked elevation of about $50 \%$ of circulating leptin, as happens in many obese human subjects in diabetes mellitus, in insulin resistance syndrome, in Cushing's syndrome, in mice without brain insulin receptors, and in rats with ablation or VMH or other hypothalamic lesions $(11,12,27,28)$. Plasma leptin levels strongly correlate with adipose tissue mass; thus, the high level of leptin may be a consequence of an increase in adipose tissue mass (29). Indeed, our manipulated mice can be considered to be leptin resistant because they are overweight with high levels of hormone. An endocrine feedback mechanism between insulin and leptin has been described: insulin is adipogenic and increases the production of leptin, while leptin decreases insulin production (30). The suppressive effect of leptin on insulin production is mediated by the autonomic nervous system and by direct action on $\beta$ cells (30). Thus, in the presence of hyperinsulinism, the hyperleptinemia suggests that the development of insulin resistance may occur either in the pancreatic $\beta$ cells or at levels of neurons in the central nervous system and their downstream targets $(30,31)$.

The manipulated adult mice also present high plasma levels of ACTH and corticosterone, and therefore a permanent dysregulation in feedback mechanisms in the HPA may be hypothesized. The disruption of feedback mechanisms can occur through a number of pathways $(32,33)$. Indeed, the administration of GC in the neonatal period produces in adults a decrease in the expression of GC receptors in several areas of the brain, and this could explain the disruption of feedback mechanisms (34). High levels of plasma corticosterone and/or ACTH are found in other models of obesity in rodents $(35,36)$, and in humans, the HPA seems to contribute to the metabolic syndrome (37). Moreover, cortisol is elevated in patients with type 1 and diabetes, and in many of them, GC administration 
does not suppress the HPA response; this suggests that GC negative feedback is impaired at hypothalamic levels $(38,39)$. As suggested by Strack et al. (40), excessive activity of GC is a possible contributor to insulin resistance and could explain the association with obesity and dyslipidemia.

In conclusion, in agreement with Cincotta et al. (41) and Portha (42), the present data show that marked hyperphagia and genetic defects are not necessary for the development of metabolic alterations, which may lead to features of type 2 diabetes mellitus. In addition, our findings support the importance of neonatal and environmental factors in the triggering and development of mild obesity features in adulthood, at least in rodents. Moreover, they support the hypothesis that overweight/obesity (and perhaps also type 2 diabetes) can be a "disorder of the brain" as suggested by others (10). Prospectively, as pure speculation, our data suggest that human babies subjected to minimal repeated manipulations during critical periods of development, such as premature newborns (and perhaps even during intrauterine life, also as an imbalance of HPA hormones, as it is suggested in rodent models) could have an elevated risk of developing obesity and derangement of metabolic parameters, possibly leading to type 2 diabetes mellitus (43). Finally, gaining knowledge of the pathogenesis of these conditions will provide the possibility of a new prevention strategy.

Acknowledgments. Some metabolic data were produced with the help of Dr. Antonio d'Amore and Dr. Paola Capriani. We express deep gratitude to Prof. Federico Bennardini and Dr. Maurizio Mian for advice on the manuscript, to Dr. Roberta Pacifici for leptin analysis data, to Carla Campanella for editorial work, and to Fiona Lewis for the English revision of the manuscript. Stefano Fidanza and Adriano Urcioli provided excellent animal care.

\section{REFERENCES}

1. Godfrey KM, Barker DJ 2001 Fetal programming and adult health. Public Health Nutr 4:611-624

2. Dietz WH 1994 Critical periods in childhood for the development of obesity. Am J Clin Nutr 59:955-959

3. Mokdad AH, Bowman BA, Ford ES, Vinicor F, Marks JS, Koplan JP 2001 The continuing epidemics of obesity and diabetes in the United States. JAMA 286:11951200

4. Zimmet P 2003 The burden of types 2 diabetes: are we doing enough? Diabetes Metab 29:S9-S18

5. Bell PM 1997 Dietary and lifestyle factors contributing to insulin resistance. Proc Nutr Soc 56:263-272

6. Holness MJ, Langdown ML, Sugden MC 2000 Early-life programming of susceptibility to dysregulation of glucose metabolism and the development of type 2 diabetes mellitus. Biochem J 349:657-665

7. Park IS, Bendayan M 1993 Development of the endocrine cells in the rat pancreatic and bile duct system. Histochem J 25:807-820

8. Schmidt M, Enthoven L, van der Mark M, Levine S, de Kloet ER, Oitzl MS 2003 The postnatal development of the hypothalamic-pituitary-adrenal axis in the mouse. Int J Dev Neurosci 21:125-132

9. Catargi B, Rigalleau V, Poussin A, Ronci-Chaix N, Bex V, Vergnot V, Gin H, Roger $\mathrm{P}$, Tabarin A 2003 Occult Cushing's syndrome in type-2 diabetes. J Clin Endocrinol Metab 88:5808-5813

10. Das UN 2002 Is type 2 diabetes mellitus a disorder of the brain? Nutrition 18:667-672

11. Bruning JC, Gautam D, Burks DJ, Gillette J, Schubert M, Orban PC, Klein R, Krone W, Muller-Wieland D, Kahn CR 2000 Role of brain insulin receptor in control of body weight and reproduction. Science 289:2122-2125

12. Kageyama A, Hirano T, Kageyama H, Osaka T, Namba Y, Tsuji M, Adachi M, Inoue S 2002 Distinct role of adiposity and insulin resistance in glucose intolerance: studies in ventromedial hypothalamic-lesioned obese rats. Metabolism 51:716-723

13. Obici S, Feng Z, Karkanias G, Baskin DG, Rossetti L 2002 Decreasing hypothalamic insulin receptors causes hyperphagia and insulin resistance in rats. Nat Neurosci 5:566-572
14. Carvalheira JB, Ribeiro EB, Araujo EP, Guimaraes RB, Telles MM, Torsoni M, Gontijo JA, Velloso LA, Saad MJ 2003 Selective impairment of insulin signalling in the hypothalamus of obese Zucker rats. Diabetologia 46:1629-1640

15. D'Amore A, Mazzucchelli A, Renzi P, Loizzo A 1996 Effect of naloxone on the long- term body weight gain induced by repeated postnatal stress in male mice. Behav Pharmacol 7:430-436

16. Loizzo A, Loizzo S, Lopez L, D'Amore A, Renzi P, Spampinato S, Di Carlo S, Bacosi A, Zuccaro P, Pacifici R 2002 Naloxone prevents cell-mediated immune alteration in adult mice following repeated mild stress in the neonatal period. Br J Pharmacol 135:1219-1226

17. Uysal KT, Wiesbrock SM, Marino MW, Hotamisligil GS 1997 Protection from obesity-induced insulin resistance in mice lacking TNF-alpha function. Nature 389:610-614

18. Maggisano V, Chiarotti F, Botunac I, Campanella C, Galietta G, Loizzo A 2005 Adolescence as possible critical temporal window for blood pressure short term monitoring in boys and girls. Eur J Epidemiol 20:517-524

19. Heal JW 1975 An animal activity monitor using a microwave Doppler system. Med Biol Eng 13:317

20. Bhatnagar S, Bell ME, Liang J, Soriano L, Nagy TR, Dallman MF 2000 Corticosterone facilitates saccharin intake in adrenalectomized rats: does corticosterone increase stimulus salience? J Neuroendocrinol 12:453-460

21. Ozanne SE 2001 Metabolic programming in animals. Br Med Bull. 60:143-152

22. Surwit RS, Feinglos MN, Rodin J, Sutherland A, Petro AE, Opara EC, Kuhn CM, Rebuffe-Scrive M 1995 Differential effect of fat and sucrose on the development of obesity and diabetes in C57BL/6J and A/J mice. Metabolism 44:645-651

23. Loizzo A, Capasso A, Galietta G, Severini C, Campana G, Spampinato S 2003 Vas deferens response to selective opioid receptor agonists in adult mice is impaired following postnatal repeated mild stress. Eur J Pharmacol 458:201-205

24. Kalman R, Adler JH, Lazarovici G, Bar-On H, Ziv E 1993 The efficiency of sand rat metabolism is responsible for development of obesity and diabetes. J Basic Clin Physiol Pharmacol 4:57-68

25. Bray GA 1995 The syndromes of obesity: an endocrine approach. In: DeGroot LJ (ed) Endocrinology. WB Saunders, Philadelphia, pp 2624-2662

26. Hotamisligil GS 2004 Inflammation, TNF $\alpha$ and insulin resistance. In: LeRoith D, Taylor SI, Olefsky JM (eds) Diabetes Mellitus: A Fundamental and Clinical Text. Lippincott Williams \& Wilkins, Philadelphia

27. Widjaja A, Schurmeyer TH, Von zur Muhlen A, Brabant G 1998 Determinants of serum leptin levels in Cushing's syndrome. J Clin Endocrinol Metab 83:600-603

28. Maffei M, Fei H, Lee GH, Dani C, Leroy P, Zhang Y, Proenca R, Negrel R, Ailhaud G, Friedman JM 1995 Increased expression in adipocytes of ob RNA in mice with lesions of the hypothalamus and with mutations at the db locus. Proc Natl Acad Sci U S A 92:6957-6960

29. Dua A, Hennes MI, Hoffmann RG, Maas DL, Krakower GR, Sonnenberg GE, Kissebah AH 1996 Leptin: a significant indicator of total body fat but not of visceral fat and insulin insensitivity in African-American women. Diabetes 45:1635-1637

30. Kieffer TJ, Habener JF 2000 The adipoinsular axis: effects of leptin on pancreatic beta-cells. Am J Physiol Endocrinol Metab 278:E1-E14

31. Seufert J, Kieffer TJ, Leech CA, Holz GG, Moritz W, Ricordi C, Habener JF 1999 Leptin suppression of insulin secretion and gene expression in human pancreatic islets: implications for the development of adipogenic diabetes mellitus. J Clin Endocrinol Metab 84:670-676

32. Barden N, Reul JM, Holsboer F 1995 Do antidepressants stabilize mood through actions on the hypothalamic-pituitary-adrenocortical system? Trends Neurosci 18:6-11

33. De Kloet ER, Vreugdenhil E, Oitzl MS, Joels M 1997 Glucocorticoid feedback resistance. Trends Endocrinol Metab 8:26-33

34. Bakker JM, van Bel F, Heijnen CJ 2001 Neonatal glucocorticoids and the developing brain: short-term treatment with life-long consequences? Trends Neurosci 24:649-653

35. Guillaume-Gentil C, Rohner-Jeanrenaud F, Abramo F, Bestetti GE, Rossi GL, Jeanrenaud B 1990 Abnormal regulation of the hypothalamo-pituitary-adrenal axis in the genetically obese fa/fa rat. Endocrinology 126:1873-1879

36. Takao T, Tojo C, Nishioka T, Hashimoto K 2000 Increased adrenocorticotropin responses to acute stress in Otsuka Long-Evans Tokushima fatty (type-2 diabetic) rats. Brain Res 852:110-115

37. Byrne CD 2001 Programming other hormones that affect insulin. Br Med Bull 60:153-171

38. Roy MS, Roy A, Gallucci WT, Collier B, Young K, Kamilmaris TC, Chrousos GP 1993 The ovine corticotropin-releasing hormone stimulation test in type 1 diabetic patients and controls: suggestion of mild chronic hypercorticosolism. Metabolism 42:696-700

39. Hudson JL, Hudson MS, Rothschild AJ, Vignati L, Schatzberg AF, Melby JC 1984 Abnormal results of dexamethasone suppression tests in nondepressed patients with diabetes mellitus. Arch Gen Psychiatry 41:1086-1089

40. Strack AM, Horsley CJ, Sebastian RJ, Akana SF, Dallman MF 1995 Glucocorticoids and insulin: complex interaction on brown adipose tissue. Am J Physiol 268:R1209_ R1216

41. Cincotta AH, Luo S, Zhang Y, Liang Y, Bina KG, Jetton TL, Scislowski PW 2000 Chronic infusion of norepinephrine into the VMH of normal rats induces the obese glucose-intolerant state. Am J Physiol Regul Integr Comp Physiol 278:R435-R444

42. Portha B 2003 [Transmitted beta-cell dysfunction as a cause for type 2-diabetes]. Med Sci (Paris) 19:847-853

43. Lesage J, Del-Favero F, Leonhardt M, Louvart H, Maccari S, Vieau D, Darnaudery M 2004 Prenatal stress induces intrauterine growth restriction and programmes glucose intolerance and feeding behaviour disturbances in the aged rat. J Endocrinol 181:291-296 